\title{
Adjustment reactions and bereavement in the elderly George Gournas
}

Address: Department of Psychiatry, "Sotiria" Hospital, Athens, Greece

from International Society on Brain and Behaviour: 3rd International Congress on Brain and Behaviour

Thessaloniki, Greece. 28 November - 2 December 2007

Published: 17 April 2008

Annals of General Psychiatry 2008, 7(Suppl I):S22 doi:10.1186/1744-859X-7-SI-S22

This abstract is available from: http://www.annals-general-psychiatry.com/content/7/SI/S22

(c) 2008 Gournas; licensee BioMed Central Ltd.

In this presentation, adjustment reactions are considered as a maladaptive reaction to the loss of a previous state of life and are differentiated from bereavement, a psychological and emotional response, and from Major Depression and other Psychiatric disorders. Bereavement and old age are approached as the emotionally charged factors which both are characterized by the common element of loss, lead to a crisis, demanding changes and setting off reactions in order to achieve a more functional adjustment. 